\title{
Study on Contact between Construction and Vision in New Digital Methods
}

\author{
Shicun Sun ${ }^{* 1, a}$, Zesong Wei², b \\ ${ }^{1}$ Faculty of Architecture, Civil And Transportation Engineering, Beijing University Of Technology Beijing, China \\ ${ }^{2}$ Architecture and Art School Beijing, Jiao tong University Beijing, China
}

\begin{abstract}
In the form language of architectural design, the process of form generation and the source of form are completely different from the perspective of construction and vision. The two traceability for form are opposite. This paper attempts to quantify and analyze the process in a creative way of digital, by summarizing the relevant digital research of forms, a feasible modular sequence is proposed, which can correspond the form evaluation based on construction and vision in architectural design, and provide an actionable way by digital for the form design language.
\end{abstract}

\section{Introduction}

In the design language of architectural form, the perspective of construction and the perspective of vision are the dividing lines of research. Although the ultimate goal leads to the expression of architecture -- form, they have completely different interpretations on the process of form generation and the source of form.

\section{The contradiction between construction and vision}

\subsection{Differrent Direction of Form}

From the perspective of construction cultural, Kenneth Frampton show viewpoints in his book Studies in Tectonic Cultural, the different forms restore to the response that different architect faces rich and full of detail construction problems in the complicated history of architecture, built based on the dual choice between the construction difficulty and the creator's subjective experience. On the other hand, the research in field of vision pays more attention to the initiative of people in recognizing on architecture form. In the tracing of formalism, the reality of matter is obscured, and the so-called reality exists in their own vision. Le Corbusier said: "Primitive man... In determining the shape of the fence, the shape of the hut, the position of the altar and other objects, he instinctively took right angles, axes, squares, circles, because he could not create anything else that would make him feel that he was creating......

Geometry is the language of man. In Le Corbusier's restoration of the original form, people have no cultural burden or even no technical constraints. In form, Perot argues, "the balance and equivalence of quantity, size and location is so obvious that if something goes wrong, you can't miss it." Therefore, the degree of perfection of the form is equal to anyone, and is a kind of concreteness beyond the material.

\subsection{Digital Clue}

The two methods of form searching are opposite in many aspects, such as the apriority of formal generation and the adaptability of construction methods. Then, if we can quantify the analysis process of them, so as to establish a measurable relationship between them, to understand and evaluate the form better? In fact, relevant research has become inevitable in today's digital society, and digital study of form has always been in the two different generating processes.

\section{Digital sequence of construction}

In terms of construction, especially based on the study of classical architecture, it is generally believed that the style presented by architectural form shows a trend of development, prosperity and decline over time. Liang Sicheng once believed that Chinese ancient architecture gradually lost its origin of construction and declined since the Han and Tang dynasties.

But from the view of hierarchy construction, the development of Chinese timber structure architecture could happen to be rational. In the architectural remains of Tang Dynasty, there were different degrees of collapse and fracture of wooden components. Therefore, the detailed decomposition of wooden components in Ming and Qing Dynasties should be a beneficial attempt for the development of architectural hierarchy. 


\subsection{History Study by Digital}

Ordinary people only find small bracket sets without noticing that the opening room becomes larger and the number of connections between pillars is increased. The bay of Hanyuan Hall in tang Dynasty is only $5.3 \mathrm{~m}$, far smaller than the size of Ming and Qing Dynasties. The span of the open room at the Meridian Gate of the Imperial Palace is $9.15 \mathrm{~m}$, and the hall of Taihe is $8.44 \mathrm{~m}$. More stress from roof must be spread on bracket set by increasing size of the bay.

The brackets of the Ming and Qing dynasties were finally connected into strips through scale reduction and compaction, which is equivalent to adding a horizontal solid wooden truss between the columns and the roof. In the case of building scale increasing, it is a general trend that the constructing scale becomes smaller and the components continue to shrink and be hierarchized, which actually influences the development of architectural art.

\subsection{Contemporary Development}

The development of contemporary technology includes the progress of materials and processing technology corresponding to the progress of human understanding. With the realization of smaller material scale, clearer digital hierarchical clues can be seen. In the model diagram of Frei Otto, the development of human architecture is a process that the structure gets lighter with geometric progression. His model diagram covers almost all the major construction types of human beings, and we can find the gradual process of architecture from single to hierarchy, from small space to large space. The branching structure proposed by Otto shows the scale model of hierarchical development. for human technology, three to four layer system is enough, but actually a lot of physical level in nature has reached the level 7 above, the superiority of the hierarchical structure often appears in the architecture more challenging. (fig1)

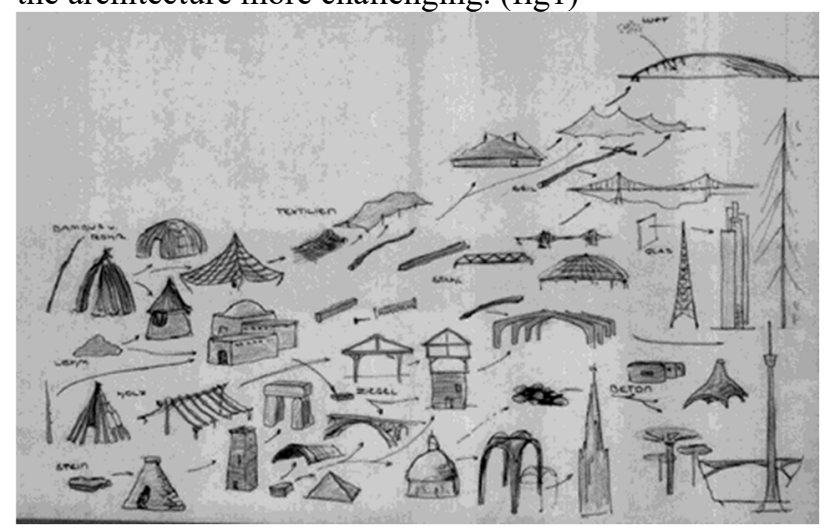

Fig1. The influence of construction on form

\subsection{Formula for construction}

Such comparisons by Frei Otto calls "BIC," a unit that reflected the lightness of the structure and the efficiency of the material. Otto used the "Tra" to represent the ability of load transmission, which is product of structural load $\mathrm{F}$ and the distance $\mathrm{S}$. The product of force and displacement is a scalar, so "Tra" is independent of direction: Tra $=\mathrm{F} \bullet \mathrm{S}$. The level of construction is expressed by the ratio of the total amount of material used to "Tra": Bic $=\mathrm{m} /$ Tra.

This formula can be derived: when the building increases the working distance and $\mathrm{S}$ magnifies, if the hierarchy of the structure is not changed, the cubic mode increase of the material mass is intolerable by the force on the material section $\mathrm{F}$ in square mode. Therefore, in the ideal construction, large buildings must reduce the weight, so the final effect is that large buildings become proportionally lighter. In Jorn Utzon's ideal, the thickness of the structural layer of The Sydney Opera House is a thin shell of $100-500 \mathrm{~mm}$. Finally, due to the difficulty of the structure, the hierarchy are increased repeatedly. Even so, the average section of the rib is only about one meter, and the ratio is close to 0.02 for the height and span of nearly 50 meters. In the hierarchy magnification brought about by technological development, the digital sequence is gradually presented, which enables us to understand that the development of construction form has a clear corresponding relationship with scale and hierarchy.

\section{Digital sequence of vision}

As a tradition of formal studies since classical architecture, the abstract study of vision has more advantages in terms of numbers and proportions. Contemporary studies of proportionality are based on the psychology. The visual form of architecture is expressed by the relationship between local and overall scales. In contrast, the real scale of architecture in the material world is the result of the interaction between material needs and realization.

\subsection{Psychology Basis}

In phenomenology of perception, the size of things are not consistent with the physical reality in limited field of vision, in psychological experiments, when a train on a drive to, due to do with the person's psychology, the increase of vehicle speed is very fast, the closer to the observer, the greater it gets faster, on the other hand, when the train left, the extent of smaller of vehicles becomes flat, which shows the visual are under the effect of psychological adjustment range of size change.

Perception is the size of the human mind. Constancy is human perception to the adjustment of the real things, the constancy means in a certain range, an individual's perception to the object size is not completely changes over distance, also does not change with the size of the retina video, despite the observation distance are different, the psychological perception of size are similar to actual size object, in the perception of objects, the individual learns to take the distance to the observer into account, the constancy comes from the relationships of things and organization. Therefore, only by putting architecture into the environment, finding the corresponding digital sequence, and reflecting the characteristics of architecture on the hierarchy, can it bring the form adapted to human psychology. 


\subsection{Modular}

As Van der Laan says, "God makes things infinitely small, infinitely large, and infinitely many, but he does not allow us to search for the limits of the universe (in search). What we can do is to extract our own yardage from the chaos that nature presents to us... In terms of measuring methods, Le Corbusier established a set of "Modular" based on the visual study of the digital hierarchy, which was a deepening of classical proportions. Compared with the classical module, his sequence with the core of human scale can be expanded and shrunk infinitely, so that the creation brought by technological development -- the smallest section, as well as smaller components such as steel tubes and window frames can be incorporated into the graphical system. As early as Augustus Perot, a smaller standard size was adopted. He used 1/3 column diameter as the modulus to cope with the complex changes derived from the classical foundation. Only by reducing the modulus could the various scale elements be visually unified.

\subsection{Size Type and Size Level}

The Corbusier's red and blue ruler modulus provides a continuous digital sequence on a human scale that is selfsimilar and complex enough to create a grid of various proportions. But such precise digital are not for function alone, they are more for the eyes than for the body. In the system of series generation, dimensions have intrinsic correlation. In the experiments of Gestalt psychology, people who do not understand the internal laws of sequence can also perceive gestalt and get psychological comfort and pleasure. On this basis, Richard Padovan decomposed his continuous numerical range into various grades of coherent dimensions, corresponding to centimeter, meter, and ten-meter scales respectively, with the internal ratio of the same sequence not exceeding $1 / 15$.

Similarly, van der Laan's shape number sequence is based on the recognition and comparison, and he finds that human cognition is not directly coordinated between large and small. His experiments on pebbles summarized the size into two concepts: size type and size level. In the same size type, there is no proportion problem even with digital difference, while in the same size level, the comparison of size type brings the proportion problem, which presents a critical points of things. In fact, Le Corbusier also developed the concept of size level in his modular system. He used 1.83 meters as a unit (Megan), by converting it into logarithms, an intuitive sequences could be formed from the galactic diameter to the light wavelength and from the largest to the smallest scale in nature, with a total of 131 modular levels.

\subsection{Digital Sequence for Visual}

From the Fibonacci sequence to almegan and shape number, the order is not the end of human knowledge, as Einstein said: through its choice ability, the mind has put the natural process into the framework or pattern selected by itself, in the process of founding the system of the law, the mind is viewed as getting what it put in nature once again. At last, patterns or digital sequence are simply things we create to explain nature and give a reason to our creations.

\section{Digital hierarchy of vision and construction}

In short, the digital sequence of form can provide diagrams from both the visual and construction. Once the digital sequence is established as the core of the diagram, the scale of construction is easy to establish a visual coordination relationship, and design becomes a behavior with rules to follow. Based on the interval of human body scale, the sequence of modern architecture develops in both large and small directions at the same time. And this sequence is not continuous presenting a kind of exponential rule.

We can list the following digital diagram: Assume that the same construction volume is broken down into different digital level, from without cutting to the surface level of processing, can be roughly corresponding to visual features in different levels of construction. The segmentation method based on typical construction scale, from $6 \mathrm{mx} 6 \mathrm{~m}$ to $0.03 \times 0.03$, which can be compared to: building (convex-concave , $3 \mathrm{~m}$ ) - architectural component (pillars, 1m) - building node (overhangs, $0.3 \mathrm{~m}$ etc.), building skin (walls, $0.1 \mathrm{~m}$ ) - building surface (such as brick work joints or drawing, almost 0 ), such a sequence is a multiple of 3 basic regressive sequence, is corresponding to the visual digital modular in the building.(table 1)

TABLE: digital hierarchy of vision and construction

\begin{tabular}{|c|c|c|c|c|c|c|}
\hline Visual scale & independent & shape & component & node & skin & surface \\
\hline scale & $6 \mathrm{M}$ & $3 \mathrm{M}$ & $1 \mathrm{M}$ & $0.3 \mathrm{M}$ & $0.1 \mathrm{M}$ & $0.03 \mathrm{M}$ \\
\hline scale ratio & 1 & $1 / 2$ & $1 / 6$ & $1 / 20$ & $1 / 60$ & $1 / 200$ \\
\hline Visual elements & 1 & 8 & 36 & 400 & 3600 & 40000 \\
\hline Geometric series & $2 \wedge 0$ & $2 \wedge 3$ & $2 \wedge 6$ & $2 \wedge 9$ & $2 \wedge 12$ & $2 \wedge 15$ \\
\hline hierarchy & single & frame & pile & brace & cyber & wave \\
\hline
\end{tabular}




\section{Conclusion}

To sum up, hierarchical sequences could be generated during the construction process. The lower level and smaller scale of construction, the higher freedom of expression in the form (can be organized by more visual elements), but the clarity and strength of the vision will decrease (from the convex and concave scale of the datum). The significance of digital hierarchy lies in that architects can make their own choices among different digital levels, weakening some levels while emphasizing others through different technical solutions. Generally speaking, an architect does not cover all levels, but tends to choose a clear set of construction sequences. Through visual psychology, the perception experience in different levels is examined and compared, so as to realize the perfect harmony between construction and visual form.

\section{References}

1. Le Corbusier, Vers une architecture, Editions Flammarion, 2008-9-1

2. Le Corbusier, Le Modulor and Modulor 2, Birkhuser Architecture Press, 2000

3. Liang Ssu-cheng, (edited by Wilma Fairbank), A pictorial history of Chinese architecture, MIT Press, 1984

4. Erdinger, Winfried, Frei Otto, Complete Works, Lightweight Construction, Springer Verlag,2005

5. Richard Padovan, Proportion, Science, Philosophy, Architecture, Spon Press, 1999

6. Bernard Cache, Digital Semper, (edited by Cynthia Davidson). Cambridge, Mass.: MIT Press, 2000.

7. M. Young, The Technical Writer's Handbook. Mill Valley, CA: University Science, 1989.

8. Kenneth Frampton, Studies in Tectonic Culture: The Poetics of Construction in Nineteenth and Twentieth Century Architecture. Cambridge, Mass.: MIT Press, 1995.

9. David Leatherbarrow, The Roots of Architectural Invention: Site, Enclosure, Materials. New York: Cambridge University Press, 1993.

10. John Ruskin, The Seven Lamps of Architecture, Dover Publications Press ,1989 